\title{
O Índice de Capital Humano: um desafio para o Brasil
}

\author{
The Human Capital Index: a challenge for Brazil
}

Nilson do Rosário Costa (https://orcid.org/0000-0002-8360-4832) ${ }^{1}$

Elize Massard da Fonseca (https://orcid.org/0000-0003-3847-3105) ${ }^{2}$

${ }^{1}$ Departamento de Ciências Sociais, Escola Nacional de Saúde Pública Sérgio Arouca, Fundação Oswaldo Cruz. R. Leopoldo Bulhões 1480, Manguinhos.

21041-210 Rio de Janeiro

RJ Brasil.

nilsondorosario@gmail.com

${ }^{2}$ Fundação Getúlio Vargas.

São Paulo SP Brasil.

\begin{abstract}
The article analyzes the Human Capital Index (HCI) proposed by the World Bank in 2018 to evaluate the performance in the health and education sectors of 157 countries. Brazil's situation is compared to societies with institutionalized social protection systems. It reveals that the condition of Brazil in HCI is deficient due to the poor performance of the education sector and the lack of control of violence against young people.

Key words Human Capital, World Bank, Health policy, Education, Social protection
\end{abstract}

Resumo $O$ artigo discute o Índice de Capital Humano (ICH) proposto pelo Banco Mundial em 2018 para avaliar o desempenho das áreas de saúde e educação de 157 países. A situação do Brasil é comparada com sociedades com sistemas de proteção social institucionalizados. Demonstra-se que a condição do Brasil no ICH é sofrível em função do baixo desempenho do setor educacional e da falta de controle da violência sobre os jovens.

Palavras-chave Capital Humano, Banco Mundial, Política de saúde, Educação, Proteção social 


\section{Introdução}

O Banco Mundial (BM) lançou em outubro de 2018 o Índice de Capital Humano (ICH) com o objetivo de apontar caminhos para o crescimento econômico e redução da pobreza em escala global. O ICH mostra as chances de sobrevivência de crianças e adultos e os resultados da área de educação de 157 países. O ICH oferece um importante painel da condição de acesso à assistência em saúde e à educação ${ }^{1}$.

$\mathrm{O}$ ICH é composto pela taxa de mortalidade de menores de cinco anos, tempo de frequência à escola, tempo de frequência à escola ajustado pelo desempenho em provas internacionais, taxa de retardo no crescimento de crianças até cinco anos e proporção de habitantes de 15 anos que chegaram aos 60 anos de idade.

O BM argumenta que a promoção do capital humano é a chave para desenvolvimento e prosperidade econômica. Os países campeões de capital humano - Coréia do Sul, Hong Kong, Japão e Singapura - apresentariam a combinação virtuosa de resultados expressivos nas áreas de saúde e na educação e alto produto per capita.

$\mathrm{O}$ projeto do ICH aponta uma estratégia para o crescimento e prosperidade que, indiretamente, desafia a sua histórica defesa das "reformas estruturais". Nesta abordagem expandida, o BM aposta na promoção de políticas públicas de educação e saúde como condição crucial para o desenvolvimento sustentável. Ao mesmo tempo, oferece evidências consistentes que podem ampliar a compreensão dos tomadores de decisão em ministérios das finanças nacionais sobre o desenvolvimento humano. Essa comunidade de especialistas em finanças públicas tende a se pautar pelo receituário da austeridade fiscal nas decisões alocativas, ameaçando sistematicamente o setor social dos países.

Ainda assim, a associação linear entre os resultados nacionais agregados nas áreas de saúde e educação e o produto na proposta do BM minimiza as dimensões institucionais que intervêm nos indicadores sociais das nações. A perspectiva institucionalista chama especialmente a atenção para as trajetórias singulares de desenvolvimento dos regimes de proteção social nas democracias contemporâneas e os efeitos sobre a prosperidade econômica, o bem-estar coletivo e a redução da desigualdade $^{2}$.

\section{Sistema de Proteção Social e ICH}

A literatura identifica dois padrões polarizados de regimes de proteção social ${ }^{3}$. O primeiro é o institucional redistributivo, presente na maioria nas democracias europeias. A forte intervenção da esfera pública formalizou a proteção ao trabalho, favoreceu a transferência de renda e a desmercantilização da provisão de muitos serviços sociais.

A segunda tipologia é caracterizada como regime de insegurança social por força da fraqueza dos governos como provedores na área social em geral. Neste regime, predominante principalmente na África subsaariana, a resposta às necessidades sociais dependente da ajuda estrangeira e da filantropia ${ }^{3}$.

O Gráfico 1, de uma amostra de 49 países, segundos as tipologias propostas por Esping-Andersen ${ }^{4}$ e por Gough et al. ${ }^{3}$, demonstra que os valores elevados do ICH observados pelo BM não são identificados apenas nos quatro campões asiáticos. Os valores igualmente altos do ICH estão também correlacionados aos regimes de proteção social instituídos na Europa. O resultado destes países europeus permite afirmar, por um lado, que os mecanismos institucionais de representação de interesses e de construção de consenso político presentes nas democracias têm interferido positivamente na promoção da proteção social e no crescimento do produto nas últimas cinco décadas. Por outro lado, os países com economia de mercado, porém com instituições redistributivas débeis, têm sido incapazes de produzir um pacto em torno dos objetivos de bem-estar, igualdade e eficiência econômica. Não por acidente, neste cluster em situação de "inseguridade social" estão os países com os piores indicadores de capital humano.

O centro do gráfico mostra a posição no ICH do terceiro cluster de países com sistemas de proteção social informais, dependente das famílias ou desiguais no acesso a benefícios e serviços (os países asiáticos retardatários e latino-ameri(canos) $)^{3}$. Cabe destacar o baixo índice de capital humano apresentado pelo Brasil em comparação aos países latino-americanos com menor valor PIB per capita, entre os quais Colômbia, Equador e Peru. Chama também atenção que a maioria dos países asiáticos situados no centro do gráfico apresenta índices de capital humano superiores aos dos países latino-americanos apesar da equivalência em valores do produto.

O sofrível resultado do ICH do Brasil é explicável principalmente pela violência endêmica 
que afeta a população adolescente e adulta e pelo baixo desempenho do setor de educação pública. Como mostra a Tabela 1, o Brasil teve um bom desempenho no indicador mortalidade de menores de cinco anos, favorecido pelo reconhecido progresso na área materno-infantil das últimas três décadas no país ${ }^{5}$, assim como a relativamen- te baixa proporção de retardo no crescimento de crianças até cinco anos, claro indicativo da efetividade das políticas de combate à pobreza ${ }^{6}$. Porém, o mesmo não pode ser dito em relação à violência. A literatura do campo ${ }^{6}$ comprova que as graves violações dos direitos humanos, como as execuções sumárias, atingem de modo

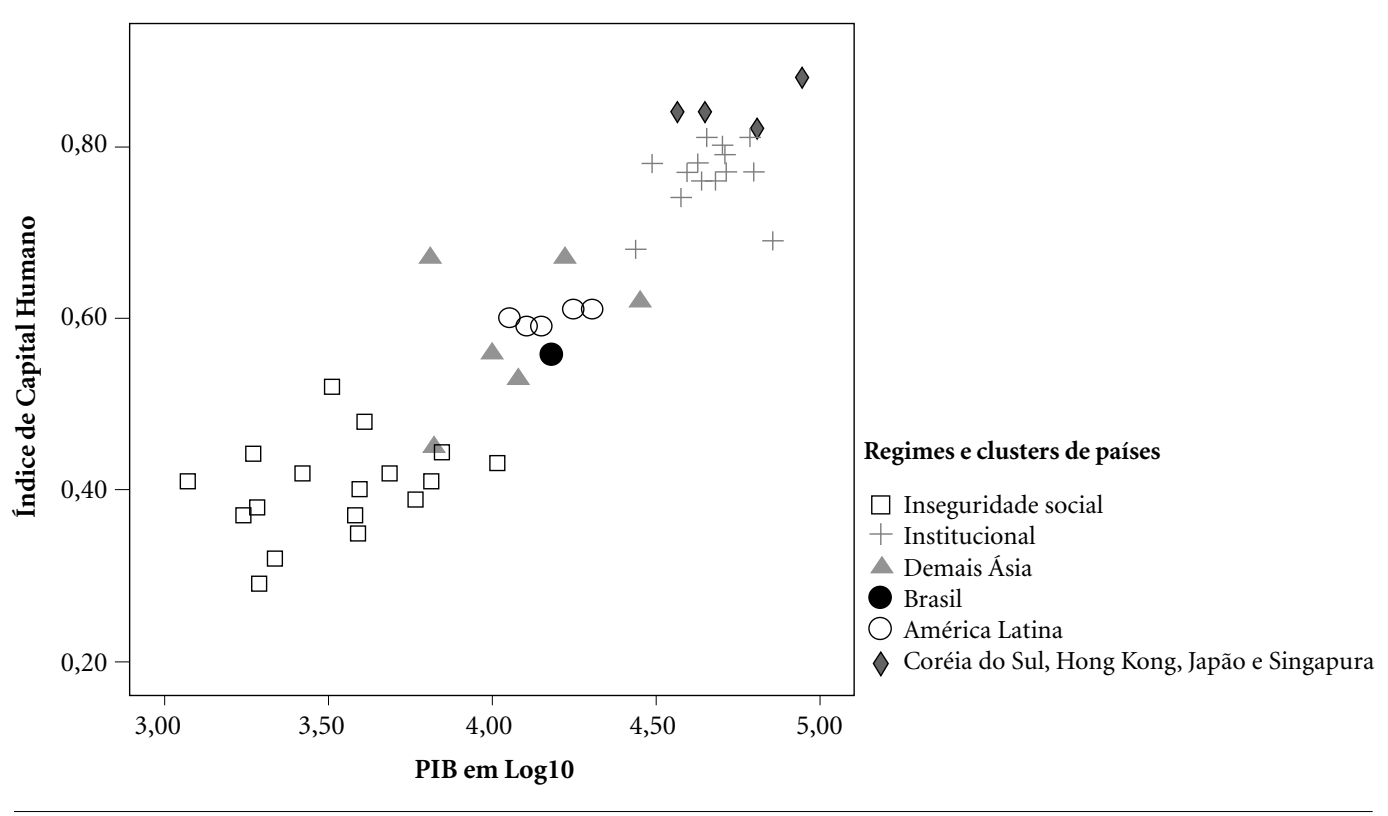

Gráfico 1. Produto Per Capita (US\$ por PPP), Índice de Capital Humano, Regime de Proteção e Cluster de Países.

Fonte: World Bank (https://www.worldbank.org/).

Tabela 1. Média dos Componentes do Índice de Capital Humano por Regimes de Proteção, Cluster de Países e Brasil, 2018 ( $\mathrm{n}=49)$.

\begin{tabular}{lccccccc}
\hline $\begin{array}{c}\text { Regimes e } \\
\text { Clusters de } \\
\text { Países }\end{array}$ & $\begin{array}{c}\text { Produto } \\
\text { Per Capita } \\
\text { (em U\$ } \\
\text { PPP) }\end{array}$ & $\begin{array}{c}\text { Probabilidade } \\
\text { de } \\
\text { sobrevivência } \\
\text { até cinco anos }\end{array}$ & $\begin{array}{c}\text { Taxa de } \\
\text { sobrevivência } \\
\text { até sessenta } \\
\text { anos }\end{array}$ & $\begin{array}{c}\text { Proporção de } \\
\text { crianças de } \\
\text { menores de 5 } \\
\text { anos com retardo } \\
\text { de crescimento }\end{array}$ & $\begin{array}{c}\text { Anos } \\
\text { na } \\
\text { Escola }\end{array}$ & $\begin{array}{c}\text { Anos na } \\
\text { Escola } \\
\text { Ajustado por } \\
\text { Desempenho }\end{array}$ & $\begin{array}{c}\text { \% de Perda } \\
\text { de Anos } \\
\text { na Escola } \\
\text { Ajustado por } \\
\text { Desempenho }\end{array}$ \\
\hline $\begin{array}{l}\text { Proteção } \\
\text { Social }\end{array}$ & 48200 & 1 & 0,94 & 0,00 & 13,6 & 11,3 & 16 \\
$\begin{array}{l}\text { Instituída (17) } \\
\text { Proteção }\end{array}$ & 24064 & 0,97 & 0,87 & 0,22 & 12,0 & 8,83 & 28 \\
$\begin{array}{l}\text { Informal (12) } \\
\text { Inseguridade }\end{array}$ & 3570 & 0,75 & 0,75 & 0,28 & 8,2 & 4,7 & 42 \\
$\begin{array}{l}\text { Social (14) } \\
\text { América }\end{array}$ & 15304 & 0,99 & 0,88 & 0.12 & 12,8 & 8,4 & 33 \\
$\begin{array}{l}\text { Latina (5) } \\
\text { Brasil }\end{array}$ & 15160 & 0,99 & 0,86 & 0,06 & 11,7 & 7,6 & 35 \\
Total (49) & 11545 & 0,97 & 0,86 & 0.13 & 11,5 & 8,4 & 28 \\
\hline
\end{tabular}

Fonte: World Bank (https://www.worldbank.org/). 
mais incisivo a população em piores condições de vida. Os homicídios com armas de fogo, por exemplo, estão associados à expansão e ao fortalecimento de diversos grupos armados nas grandes cidades e metrópoles e da intervenção do aparato repressivo estatal. Seus efeitos são o crescimento constante do número de homicídios no país, que alcançou a taxa 28,9 mortes por 100 mil habitantes em 2015, representando 10\% do total das mortes no país e a primeira causa de morte entre adolescentes ${ }^{7}$.

Em relação ao setor educacional, Prado ${ }^{8}$ chama atenção para o desempenho sofrível dos estudantes brasileiros de 15 anos de idade no Programa Internacional de Avaliação de Estudantes (PISA) de 2015, coordenado pela OCDE. Neste ano, $56,6 \%$ dos brasileiros ficaram abaixo do nível básico em ciências, 50,99\% em leitura e $70,25 \%$ no teste de matemática. A universalização do acesso ao ensino público fracassou na tarefa de desenvolver as competências básicas em áreas estratégicas em razão da baixa qualidade do ensino, dos baixos salários dos docentes, da precariedade da infraestrutura das escolas e da pobreza das famílias. Paradoxalmente, no campo educacional o Brasil está bastante próximo à

\section{Referências}

1. World Bank. The Human Capital Project. Washington: World Bank Publications; 2018.

2. Costa NR. Estado de Bem-Estar Social e Democracia. Cien Saúde Colet 2018; 23(10):3471-3471.

3. Gough I, Wood G, Barrientos A, Bevan P, Davis P, Room G. Insecurity and Welfare Regimes in Asia, Africa, and Latin America: Social Policy in Development Contexts. New York: Cambridge University Press; 2006.

4. Esping-Andersen G. The Three Worlds of Welfare Capitalism. New Jersey: Princeton University Press; 1990.

5. França EB, Lansky S, Rego MAS, Malta DC, França JS, Teixeira R, Porto D, Almeida MF, Souza MFM, Szwarcwald CL, Mooney M, Naghavi M, Vasconcelos AMN. Principais causas da mortalidade na infância no Brasil, em 1990 e 2015: estimativas do estudo de Carga Global de Doença. Rev Bras Epidemiol 2017; 2(1):46-60.

6. Monteiro CA, Benicio MHD, Conde WL, Konno S, Lovadino AL, Barros AJD, Victora CG. Narrowing socioeconomic inequality in child stunting: the Brazilian experience, 1974-2007. Bull WHO 2010; 1(88):305-311. condição de inseguridade social, a despeito do importante investimento público e privado em educação e da força da ação coletiva dos grupos de interesse setoriais.

O Brasil está fadado a sofrer vexatórias avaliações da sua capacidade de desenvolver o capital humano nos próximos anos caso não promova mudanças substantivas no funcionamento no seu sistema educacional, no controle da violência e no fortalecimento das políticas redistributivas. A dogmática reiteração da estratégia de guerra às drogas, liberação da posse de armas e a rejeição ao pacto social pelos novos incumbentes, vencedores da corrida eleitoral para o governo federal em 2018, com certeza não favorecerão o desenvolvimento do capital humano entre nós.

\section{Colaboradores}

NR Costa participou da elaboração do projeto, coleta de dados, análise dos dados, redação e revisão do artigo. EM Fonseca participou da análise dos dados, redação e revisão do artigo.
7. Souza ERS, Ribeiro AP, Souza TO, Souza CAM, Cardoso FLG, Santos TN. Homicídios e Agressões: As Faces mais Evidentes da Violência. In: Minayo MCS, Assis SM, organizadoras. Novas e Velhas Faces da Violência no Século XXI: Visão da Literatura Brasileira no Campo da Saúde. Rio de Janeiro: Editora Fiocruz; 2018. p. 81-97.

8. Prado MCRM. Educação Precária, Gargalo Brasileiro. Jornal Valor Econômico; 2017.

\footnotetext{
Artigo apresentado em 26/11/2018

Aprovado em 03/01/2019

Versão final apresentada em 05/01/2019
} 